\title{
Studi Eksperimen Penambahan Tailing Pada Campuran Mortar Sebagai Substitusi Parsial Semen Untuk Dinding Panel
}

\author{
D.R. Kurniaty ${ }^{\mathrm{a}^{*}}$ \\ ${ }^{a}$ Laboratorium Transportasi dan Jalan Raya Jurusan Teknik Sipil Universitas Tadulako, Jalan Soekarno Hatta Km. 9, Palu, Sulawesi \\ Tengah, Indonesia, 94112
}

${ }^{*}$ Corresponding author's e-mail: dianrifany@yahoo.com

Received: 25 December 2021; revised: 12 January 2022; accepted: 29 January 2022

\begin{abstract}
Poboya is located in East Palu District, Palu City, Central Sulawesi. This village is now an area that has become a traditional gold mining activity. The end result of the mining process in the form of these deposits becomes waste which is commonly referred to as tailing. This waste contains a lot of carbon and no one has utilized it. This study was conducted to determine the optimum percent value of adding tailing to the mortar mixture so that it can affect the compressive strength of the mortar. This research uses experimental methods and literature studies. The location of the research was carried out at the Laboratory of Structures and Building Materials, Faculty of Engineering, Tadulako University. The variations used in the use of gold mine waste (tailing) as partial cement substitution are 50\% and $75 \%$ by weight of cement. Tailings will replace some of the cement in a mortar mix made of sand, cement and water. The test to be carried out is the compressive strength of the mortar at the age of 7 and 28 days. Mortar test object made measuring $5 \times 5 \times 5 \mathrm{~cm}$. The results obtained showed that $50 \%$ tailings had a higher compressive strength of $156 \mathrm{~kg} / \mathrm{cm} 2$ than mortar using $75 \%$ tailing only had a compressive strength of $21.33 \mathrm{~kg} / \mathrm{cm} 2$ at the age of the specimen 28 days. Mortar is used for the manufacture of wall panels with ferrocement technology.
\end{abstract}

Keywords: tailing, ferrocement, mortar, wall panel

Abstrak: Poboya terletak di Kecamatan Palu Timur, Kota Palu, Sulawesi Tengah. Kelurahan ini sekarang menjadi areal yang menjadi aktifitas penambangan emas tradisional. Hasil akhir proses penambangan berupa endapan ini menjadi limbah yang biasa disebut dengan tailing. Limbah ini banyak mengandung karbon dan belum ada yang memanfaatkan. Penelitian ini dilakukan untuk mengetahui nilai persen optimum penambahan tailing ke dalam campuran mortar sehingga dapat berpengaruh terhadap kuat tekan mortar. Penelitian ini menggunakan metode eksperimen dan studi literatur. Lokasi penelitian dilakukan di Laboratorium Struktur dan Bahan Bangunan Fakultas Teknik Universitas Tadulako. Variasi yang digunakan dalam penggunaan limbah tambang emas (tailing) sebagai subsitusi sebagian semen adalah $50 \%$ dan $75 \%$ terhadap berat semen. Tailing akan menggantikan sebagian semen pada campuran mortar yang berbahan pasir, semen dan air. Pengujian yang akan dilakukan adalah kuat tekan mortar pada umur 7 dan 28 hari. Benda uji mortar yang dibuat berukuran 5 x 5 x $5 \mathrm{~cm}$. Hasil yang diperoleh menunjukkan bahwa 50\% tailing memiliki kuat tekan lebih tinggi sebesar $156 \mathrm{~kg} / \mathrm{cm}^{2} \mathrm{dibanding}$ mortar menggunakan $75 \%$ tailing hanya memiliki kuat tekan sebesar $21,33 \mathrm{~kg} / \mathrm{cm}^{2}$ pada umur benda uji 28 hari. Mortar digunakan untuk pembuatan dinding panel dengan teknologi ferrosemen.

Kata kunci: tailing, ferrosemen, mortar, dinding panel

\section{Pendahuluan}

Poboya adalah salah satu Kelurahan di Kecamatan Palu Timur, Kota Palu, Sulawesi Tengah. Kelurahan ini sekarang menjadi areal yang merupakan aktifitas penambangan emas tradisional, yang dahulunya merupakan kawasan pertanian, ladang dan kebun - kebun masyarakat. Kawasan ini sudah dipenuhi dengan mesin tromol pengolah emas. Proses penambangan emas yang berada diperbukitan, banyak menghasilkan limbah berupa endapan yang tidak mengandung emas lagi (Gambar 1). Hasil akhir proses penambangan berupa endapan ini menjadi limbah yang biasa disebut dengan tailing [1-4]. Limbah akhir hasil tambang tersebut masih memiliki kandungan karbon, sehingga dapat digunakan sebagai bahan pengganti parsial (sebagian) semen pada campuran mortar [5-7]. Bahan pembentuk mortar umumnya terdiri dari semen Portland, pasir dan air, dapat juga diberikan bahan tambah (admixture) ke dalam campuran mortar [8-12].

Bahan gabungan yang diperoleh dari campuran mortar semen dengan penguatan lapis kawat baja dalam bentuk jala kawat atau mesh dimana kawat jala dianggap sebagai tulangan inilah yang akan membentuk dinding panel dengan teknologi ferosemen [6].

Pada penelitian ini merumuskan masalah sebagai berikut :

1) Apakah penambahan tailing pada campuran mortar sebagai pengganti sebagian semen dapat berpengaruh terhadap kuat tekan mortar?

2) Berapa persen nilai optimum penambahan tailing ke dalam campuran mortar?

3) Apakah mortar dengan menggantikan sebagian semen dengan tailing dapat di aplikasikan sebagai bahan dinding panel dengan teknologi ferosemen?

Tujuan penelitian ini :

1) Untuk dapat mengurangi pemakaian semen dengan alternatif tailing sebagai pengikat dalam campuran mortar. 
2) Untuk mengetahui seberapa besar tailing berpengaruh terhadap kuat tekan mortar.

3) Menjadikan mortar sebagai bahan pembuat dinding panel dengan teknologi ferosemen dapat bernilai ekonomis, ramah lingkungan, dan berkualitas

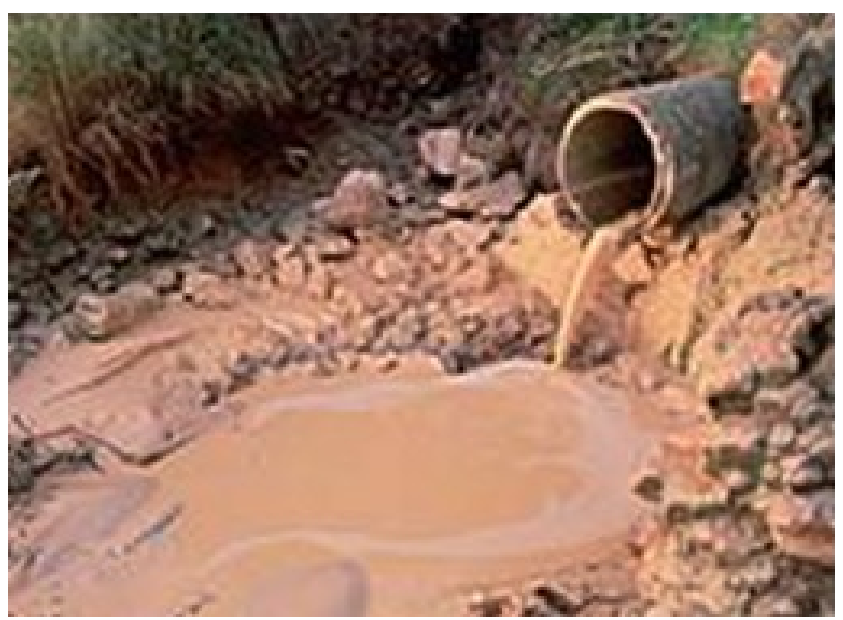

Gambar 1. Limbah akhir proses penambang emas (tailing)

Manfaat penelitian adalah :

1) Memanfaatkan limbah tambang emas (tailing)

2) Membuka peluang usaha baru bagi penambang emas, menjadikan kembali limbah akhir penambangan emas menjadi dinding panel, sehingga dapat menambah pendapatan mereka.

\section{Metode Penelitian}

Metode penelitian ini metode eksperimen yang dilakukan di Laboratorium Struktur dan Bahan Bangunan Fakultas Teknik Universitas Tadulako serta menggabungkan dengan studi literatur.

\subsection{Tailing sebagai Campuran Mortar}

Nilai kuat tekan beton dan mortar pada umur 28 hari menunjukkan hasil paling maksimum untuk beton ialah $22,17 \mathrm{MPa}$ pada variasi campuran $20 \%$ tailing dan mortar variasi campuran $5 \%$ dan $15 \%$ berturut- turut besarnya 15,4 MPa dan 14,4 MPa [13].

Penggunaan tailing 5\% dan 15\% mengalami kenaikan kuat tekan, akan tetapi penggunaan tailing $10 \%$ dan $20 \%$ justru menyebabkan penurunan kuat tekan. Kuat tekan maksimum yang diperoleh dalam penelitian ini sebesar $17,97 \mathrm{MPa}$ yaitu pada campuran mortar tipe II, dengan kadar 5\% tailing dan additive 2\% umur 28 hari. Semakin besar penggunaan additive, memiliki kecenderungan nilai kuat tekan mengalami peningkatan seiring dengan umur pengujian mortar [14].

Dalam penelitian Pandeleke (2010), disampaikan bahwa hasil akhir penambangan emas (tailing) memiliki kandungan komposisi kimia yaitu $\mathrm{CaO}, \mathrm{SiO} 2, \mathrm{Al} 2 \mathrm{O} 3$, Arsen, Hg. Beberapa unsur kimia tersebut dimiliki oleh semen seperti $\mathrm{CaO}$ dan $\mathrm{SiO} 2$. Oleh karenanya melalui pendekatan unsur kimia tersebut maka dilakukan eksperimen untuk menggantikan sebagian semen dengan tailing dalam campuran mortar [13]. Semen portland merupakan bahan perekat yang mengikat bahan bahan agregat dalam pembuatan mortar.

Bahan pembentuk ferosemen adalah mortar. Semen portland, agregat halus (pasir), air dan admixture (bahan tambah) merupakan bahan yang digunakan dalam pembuatan mortar. Berdasarkan ACI Committee 549 (1999) mortar biasanya mengandung $95 \%$ dari total volume ferosemen dan mempunyai pengaruh yang besar pada perilaku terhadap produk akhir .

\subsection{Bahan-Bahan Penelitian}

Bahan-bahan yang digunakan dalam pembuatan benda uji mortar dapat dilihat pada Tabel 1.

Tabel 1. Bahan-bahan benda uji mortar

\begin{tabular}{clcc}
\hline No & Bahan-Bahan & Type & Sumber \\
\hline 1 & Semen Portland & I & PT. Tonasa \\
\hline 2 & Pasir & $\begin{array}{c}\text { Agregat } \\
\text { halus }\end{array}$ & S. Palu \\
\hline 3 & Tailing & - & Poboya \\
\hline 4 & Air & Air Bersih & Lab. Struktur \\
\hline
\end{tabular}

\subsection{Pembuatan Benda Uji dan Rancangan Campuran Mortar}

Variasi campuran mortar terdiri dari dua campuran yaitu $50 \%$ dan $75 \%$ penggunaan limbah tambang emas (tailing) terhadap berat semen. Benda uji mortar untuk menguji kuat tekan mortar dicetak dalam cetakan mortar benda uji berbentuk kubus berukuran 5 x 5 x $5 \mathrm{~cm}$ sesuai SNI 036825-2002 tentang metode pengujian kekuatan tekan mortar semen portland untuk pekerjaan sipil [15]. Rancangan campuran mortar untuk 6 benda uji dari masing masing variasi penggunaan tailing sebagai pengganti sebagian semen adalah sebagai berikut:

1). Untuk Variasi $50 \%$

Semen Portland 500 - $250=250$ gram; (2) pasir 1.375 gram; (3) air suling $242 \mathrm{ml}$; (4) tailing $50 \%$ x $500=250$ gram.

2). Untuk Variasi $75 \%$

Semen Portland 500 - $375=125$ gram; (2) pasir 1.375 gram; (3) air suling $242 \mathrm{ml}$; (4) tailing $75 \%$ x $500=375$ gram.

Kadar air optimum pada campuran mortar untuk membuat benda uji ditetapkan berdasarkan hasil pengujian meja leleh.

\subsection{Pengujian Laboratorium}

Melakukan pengujian campuran mortar pada laboratorium Struktur dan Bahan Bangunan Fakultas Teknik Universitas Tadulako. Pengujian dilakukan 7 hari dan 28 hari, dengan variasi campuran $50 \%$ dan $75 \%$ dalam penggunaan limbah tambang emas (tailing). Pengujian yang akan dilakukan adalah pengujian kuat tekan campuran mortar, dengan benda uji ukuran $5 \times 5 \times 5 \mathrm{~cm}$. 


\subsection{Pembuatan Dinding Panel dengan Teknologi Ferosemen}

Hasil kuat tekan yang terbaik dari variasi penggunaan tailing sebagai pengganti sebagian semen pada campuran mortar, diaplikasikan penggunaannya untuk pembuatan dinding panel dengan teknologi ferosemen. Pertama yang di siapkan adalah cetakan yang terbuat dari multipleks yang dibentuk dalam 2 (dua) ukuran yaitu ukuran 1 x $40 \mathrm{~cm}$ dan 1,2 x $80 \mathrm{~cm}$. Kemudian di siapkan pula mortar decking atau selimut mortar yang dicetak dengan menggunakan pipa PVC dengan ukuran 2,5 Inch. Kegunaan mortar decking sebagai batas antara adukan dengan kawat wire mesh. Kemudian membuat rangka yang terbuat dari anyaman kawat wire mesh berfungsi sebagai tulangan (Gambar 2).
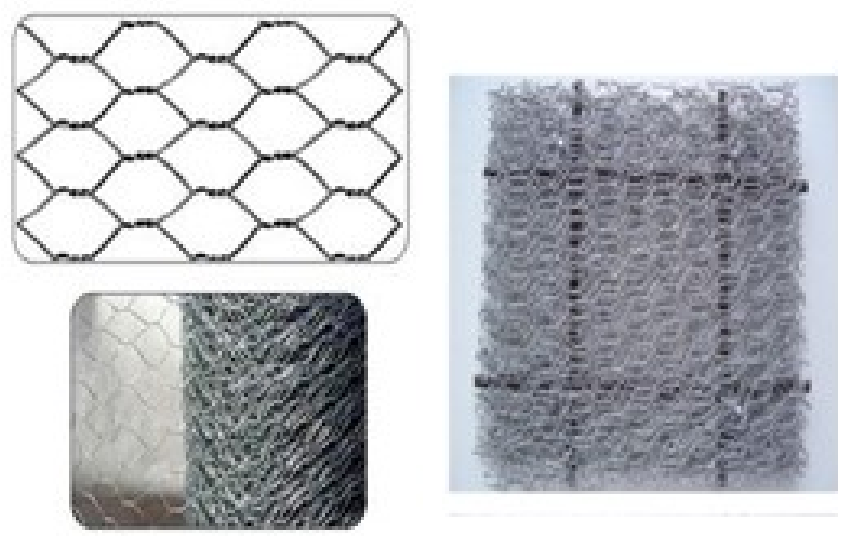

Gambar 2. Wire mesh

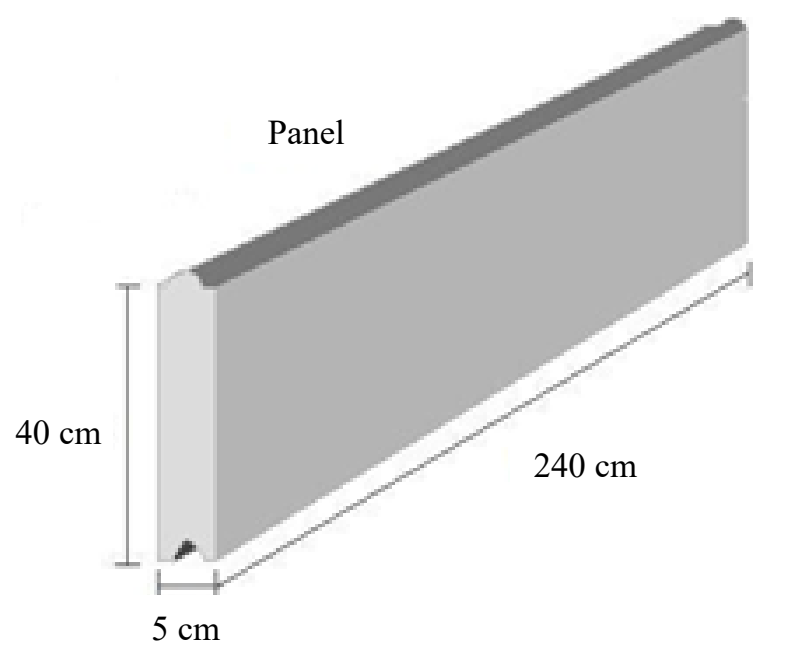

Gambar 3. Ukuran dinding panel

Selanjutnya mempersiapkan bahan untuk membuat campuran dinding panel yang terdiri dari semen, pasir, tailing dan air (Gambar 3 dan Gambar 4). Perbandingan adukan adalah dengan perbandingan berat. Perbandingan untuk konstruksi ferosemen umumnya $1: 3$ yaitu semen : pasir, dengan perbandingan semen : tailing adalah 50\%: 50\%. Faktor air semen : 0,3. Penentuan penambahan air pada campuran semen, pasir dan limbah akhir penambangan emas, didapat dengan cara trial and error sampai diperoleh kelecakan yang mencukupi. Proses pencampuran dan pengadukan dalam pengerjaan dinding panel sebagian menggunakan peralatan seperti : talam (wadah), sendok kayu, sekop, dan alat-alat manual lainnya, sedangkan untuk pencampuran menggunakan mesin molen kemudian dicetak sesuai dengan ukuran yang telah disiapkan

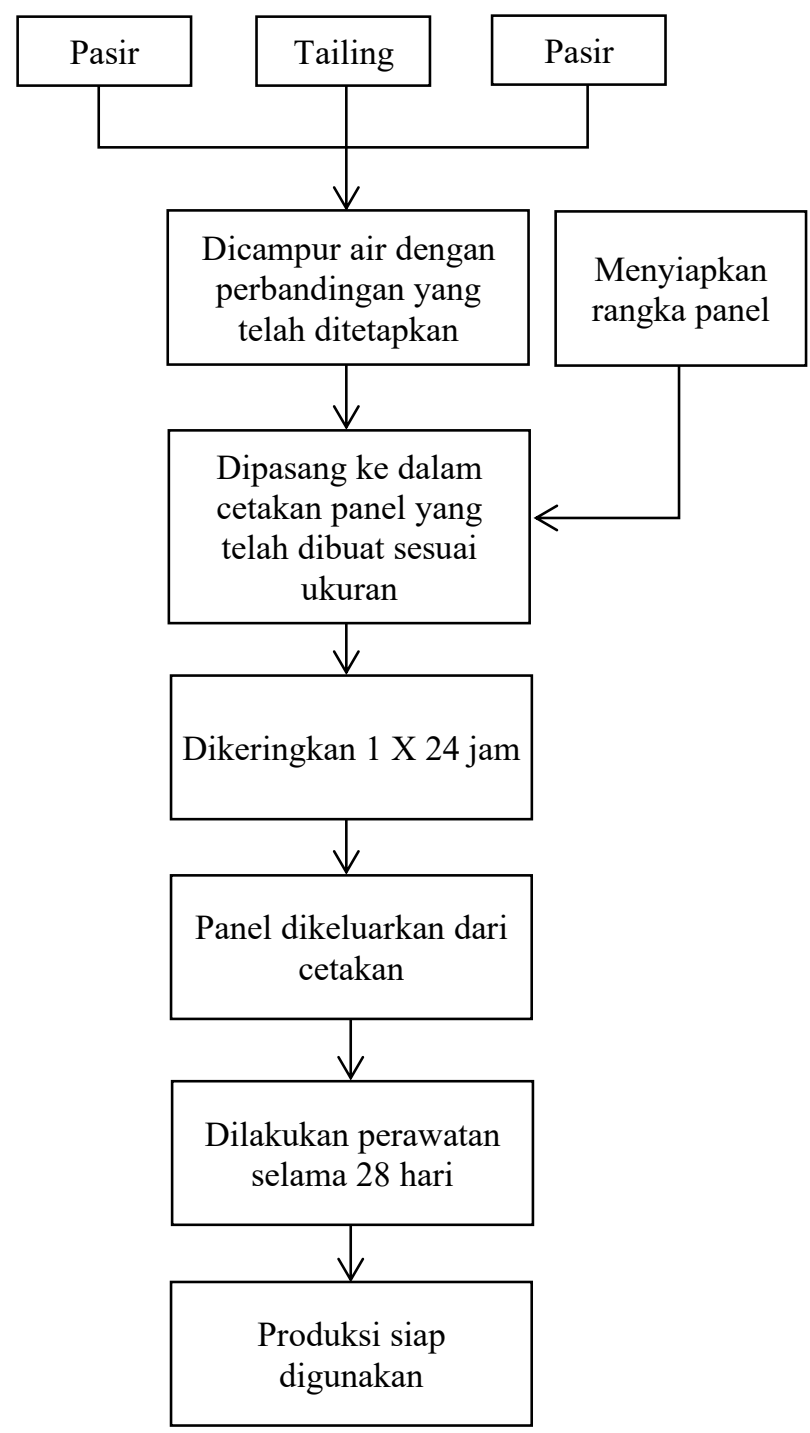

Gambar 4. Bagan alir proses pembuatan papan partikel

\section{Hasil dan Pembahasan}

\subsection{Hasil Pengujian Laboratorium}

Hasil pengujian laboratorium disajikan pada Tabel 2 dan Tabel 3. Hasil yang diperoleh menunjukkan bahwa untuk campuran mortar dengan menggunakan 50\% limbah akhir tambang emas (tailing) memiliki kuat tekan lebih tinggi yaitu sebesar $156 \mathrm{~kg} / \mathrm{cm}^{2}=15,6 \mathrm{MPa}$ pada umur benda uji 28 hari dibanding dengan campuran mortar dengan menggunakan $75 \%$ limbah akhir tambang emas hanya memiliki kuat tekan yaitu sebesar $21,33 \mathrm{~kg} / \mathrm{cm}^{2}=2,13 \mathrm{MPa}$ pada umur benda uji 28 hari.

Berbeda dengan hasil yang diperoleh dari penelitian Pandeleke, (2010) mortar variasi campuran 5\% dan 15\% berturut- turut besarnya 15,4 MPa dan 14,4 MPa [13]. 
REKONSTRUKSI TADULAKO: Civil Engineering Journal on Research and Development, Vol. 3(1), March 2022

\subsection{Hasil Produk Dinding Panel dengan Teknologi} Ferosemen

Pemanfaatan limbah akhir tambang emas (tailing) sebagai pengganti sebagian semen pada campuran mortar, persen optimum tailing yang dapat digunakan adalah sebesar 50\% dari berat semen. Sebagai aplikasi penggunaannya maka telah dibuat salah satu bentuk konstruksi sederhana yaitu dinding panel dengan teknologi ferosemen (Gambar 4).

Tabel 2. Hasil pengujian kuat tekan campuran mortar variasi tailing 50\%

\begin{tabular}{|c|c|c|c|c|c|c|c|c|c|c|c|}
\hline \multirow{3}{*}{$\begin{array}{l}\text { No } \\
\text { BU }\end{array}$} & \multirow{3}{*}{$\begin{array}{c}\text { Jenis } \\
\text { Konst. }\end{array}$} & \multirow{3}{*}{$\begin{array}{c}\text { Umur } \\
\text { BU } \\
\text { (Hari) }\end{array}$} & \multirow{3}{*}{$\begin{array}{c}\text { Berat } \\
\text { (gram) }\end{array}$} & \multicolumn{3}{|c|}{ Dimensi } & \multirow{3}{*}{$\begin{array}{c}\text { Berat } \\
\text { Isi }\left(\mathrm{gr}^{2} \mathrm{~cm}^{3}\right)\end{array}$} & \multirow{3}{*}{$\begin{array}{c}\begin{array}{c}\text { Luas } \\
\text { Bid }\end{array} \\
\text { Tes } \\
\left(\mathrm{cm}^{2}\right)\end{array}$} & \multirow{3}{*}{\begin{tabular}{|l} 
Beban \\
Maks \\
$(\mathrm{KN})$
\end{tabular}} & \multirow{2}{*}{\multicolumn{2}{|c|}{$\begin{array}{c}\text { Kuat Tekan } \\
\left(\mathrm{kg} / \mathrm{cm}^{2}\right) \\
\end{array}$}} \\
\hline & & & & \multirow{2}{*}{$\begin{array}{c}\text { Panjang } \\
\text { (cm) }\end{array}$} & \multirow{2}{*}{$\begin{array}{c}\text { Lebar } \\
(\mathrm{cm})\end{array}$} & \multirow{2}{*}{$\begin{array}{l}\text { Tinggi } \\
\text { (cm) }\end{array}$} & & & & & \\
\hline & & & & & & & & & & 7 hari & $\begin{array}{c}28 \\
\text { hari }\end{array}$ \\
\hline 1 & \multirow{6}{*}{$\begin{array}{l}\text { Mortar } \\
\text { Tailing } \\
50 \%\end{array}$} & 28 & 289,7 & 5 & 5 & 5 & 2,318 & 25 & 40 & 160 & 160 \\
\hline 2 & & 28 & 293,2 & 5 & 5 & 5 & 2,228 & 25 & 39 & 156 & 156 \\
\hline 3 & & 28 & 291,1 & 5 & 5 & 5 & 2,329 & 25 & 38 & 154 & 154 \\
\hline 4 & & 28 & 293,0 & 5 & 5 & 5 & 2,336 & 25 & 39 & 156 & 156 \\
\hline 5 & & 28 & 291,3 & 5 & 5 & 5 & 2,330 & 25 & 38 & 153 & 153 \\
\hline \multirow[t]{2}{*}{6} & & 28 & 292,2 & 5 & 5 & 5 & 2,328 & 25 & 39 & 156 & 156 \\
\hline & & & Rata-rata & & & & 2,330 & & & & \\
\hline
\end{tabular}

Tabel 3. Hasil pengujian kuat tekan campuran mortar variasi tailing 75\%

\begin{tabular}{|c|c|c|c|c|c|c|c|c|c|c|c|}
\hline \multirow{3}{*}{$\begin{array}{l}\text { No } \\
\text { BU }\end{array}$} & \multirow{3}{*}{$\begin{array}{c}\text { Jenis } \\
\text { Konst. }\end{array}$} & \multirow{3}{*}{$\begin{array}{c}\text { Umur } \\
\text { BU } \\
\text { (Hari) }\end{array}$} & \multirow{3}{*}{$\begin{array}{l}\text { Berat } \\
\text { (gram) }\end{array}$} & \multicolumn{3}{|c|}{ Dimensi } & \multirow{3}{*}{$\begin{array}{c}\text { Berat } \\
\text { Isi }\left(\mathrm{gr} / \mathrm{cm}^{3}\right)\end{array}$} & \multirow{3}{*}{$\begin{array}{c}\begin{array}{c}\text { Luas } \\
\text { Bid }\end{array} \\
\text { Tes } \\
\left(\mathrm{cm}^{2}\right)\end{array}$} & \multirow{3}{*}{$\begin{array}{c}\text { Beban } \\
\text { Maks } \\
(\mathrm{KN})\end{array}$} & \multirow{2}{*}{\multicolumn{2}{|c|}{$\begin{array}{c}\text { Kuat Tekan } \\
\left(\mathrm{kg} / \mathrm{cm}^{2}\right) \\
\end{array}$}} \\
\hline & & & & & & & & & & & \\
\hline & & & & $\begin{array}{c}\text { Panjang } \\
\text { (cm) }\end{array}$ & $\begin{array}{c}\text { Lebar } \\
(\mathrm{cm})\end{array}$ & $\begin{array}{l}\text { linggl } \\
(\mathrm{cm})\end{array}$ & & & & 7 hari & $\begin{array}{c}28 \\
\text { hari }\end{array}$ \\
\hline 1 & \multirow{6}{*}{$\begin{array}{c}\text { Mortar } \\
\text { Tailing } \\
75 \%\end{array}$} & 28 & 292,2 & 5 & 5 & 5 & 2,338 & 25 & 5 & 20 & 20 \\
\hline 2 & & 28 & 299,7 & 5 & 5 & 5 & 2,398 & 25 & 5 & 20 & 20 \\
\hline 3 & & 28 & 293,6 & 5 & 5 & 5 & 2,349 & 25 & 6 & 23 & 23 \\
\hline 4 & & 28 & 293,2 & 5 & 5 & 5 & 2,346 & 25 & 6 & 20 & 20 \\
\hline 5 & & 28 & 295,1 & 5 & 5 & 5 & 2,387 & 25 & 5 & 22 & 22 \\
\hline \multirow[t]{2}{*}{6} & & 28 & 297,4 & 5 & 5 & 5 & 2,388 & 25 & 5 & 23 & 23 \\
\hline & & & Rata-rata & & & & 2,368 & & & \multicolumn{2}{|c|}{21,33} \\
\hline
\end{tabular}

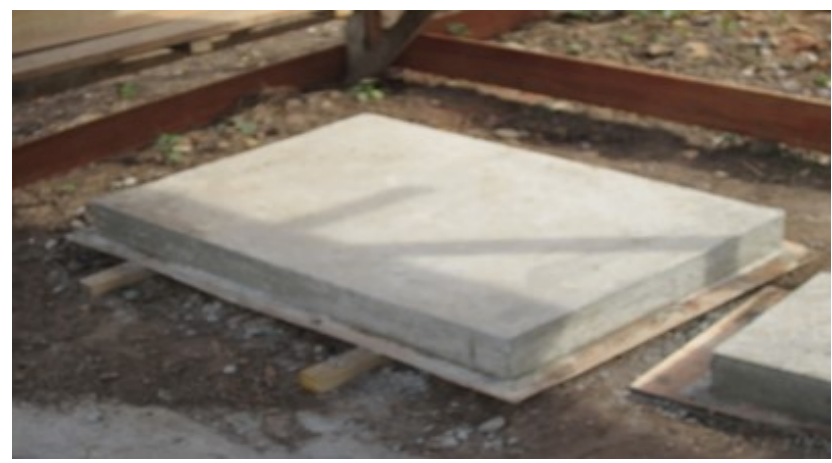

Gambar 4. Hasil jadi produk dinding panel dengan teknologi ferosemen

\section{Kesimpulan}

Berdasarkan hasil pengujian, maka dapat ditarik beberapa kesimpulan sebagai berikut :

1) Campuran mortar menggunakan $50 \%$ limbah akhir tambang emas (tailing) memiliki kuat tekan lebih tinggi yaitu sebesar $156 \mathrm{~kg} / \mathrm{cm}^{2}=15,6 \mathrm{MPa}$ pada umur benda uji 28 hari dibanding dengan campuran mortar dengan menggunakan $75 \%$ limbah akhir tambang emas hanya memiliki kuat tekan yaitu sebesar $21,33 \mathrm{~kg} / \mathrm{cm}^{2}=2,13$ MPa pada umur benda uji 28 hari.

2) Persen optimum tailing yang dapat digunakan adalah sebesar $50 \%$ dari berat semen.

3) Penggunaan tailing sebagai pengganti sebagian semen pada campuran mortar dapat diaplikasikan dalam bentuk konstruksi sederhana yaitu dinding panel dengan teknologi ferosemen.

\section{Ucapan Terima Kasih}

Penulis ucapkan terimakasih kepada Kepala Laboratorium Struktur dan Bahan Bangunan atas bimbingannya dan memberikan fasilitas untuk dapat melakukan penelitian di Laboratorium Struktur dan Bahan Bangunan. Terima kasih yang tak terhingga kepada teman teman PLP di Laboratorium tersebut yang telah membantu dalam melakukan eksperimen

\section{Daftar Pustaka}

[1] E. Rabihati, I.A. Purnama, M.S. Adjie, and V.D. Rachmawan, "Pemanfaatan Limbah Bauksit (Tailing Bauxite) Sebagai Bahan Pengganti Agregat Halus 
Terhadap Kuat Tekan, Kuat Tarik Belah, dan Modulus Elastisitas Pada Beton", Retensi: Jurnal Rekayasa Teknik Sipil, vol. 1, no. 1, p. 1, 2020.

[2] I.A. Pamayo and Y. Trihadiningrum, "Stabilisasi/Solidifikasi Timbunan Tailing Penambangan Emas Rakyat Kulon Progo Menggunakan Semen Portland", Jurnal Teknik ITS, vol. 5, no. 2, p. 242, 2015.

[3] A. Majid, A. Rohman, and R. R. Isda, "Desain Bahan Dasar Campuran Bata Ringan dari Limbah Tambang Emas Pongkor", Jurnal Teknik, vol. 17, no. 1, p. 9, 2018.

[4] I.J.R. Sondakh, M.D. J. Sumajouw, R. Pandaleke, and S.O. Dapas, "Pemanfaatan Tailing Sebagai Substitusi Parsial Pada Semen Ditinjau Terhadap Kuat Tekan dan Kuat Tarik Lentur", Jurnal Sipil Statik, vol. 3, no. 4, p. 253, 2015.

[5] Amalia and A. Murdiyoto, "Kualitas Bata Beton Berlubang Dengan Bahan Limbah Tailing Penambangan Emas UPBE Pongkor, Politeknologi, vol. 18 , no. 1 , p. $1,2019$.

[6] A.Y. Mulia and I.N. Sari, "Karakteristik Limbah Tailing Sebagai Bahan Baku Mortar Siap Pakai”, Jurnal Permukiman, vol. 13, no. 1, p. 53, 2018.

[7] S.W.M. Supit, R. Rumbayan, and S. Misilu, "Pengaruh Pemanfaatan Tailing Terhadap Kuat Tekan, Porositas dan Absorpsi Mortar Portland Composite Cement", Jurnal Teknik Sipil Terapan, vol. 1, no. 1, p. 29, 2019.
[8] S. Amrie, Teknologi Beton A-Z, Jakarta: Penerbit Yayasan John Hi- Tech Idetama, 2005.

[9] Tim Penyusun, Teknologi Bahan Bangunan, Yogyakarta: Sekolah Pasca Sarjana Universitas Gadjah Mada, 2008.

[10] T. Mulyono, Teknologi Beton, Yogyakarta: Penerbit Andi, 2004.

[11] K. Tjokrodimuljo, Teknologi Beton, Yogyakarta: Universitas Gadjah Mada, 2004.

[12] G.B. Batson, J.O. Castro, A.J. Guerra, M.E. Iorns, C.D. Johnston, A.E. Naaman, J.P. Romualdi, S.P. Shah, R.F. Zollo, N. Swamy, B.L. Tilsen, R.B. Williamson, and R.C. Zubieta, "Guide for the Design, Construction, and Repair of Ferrocement". ACI Structural Journal, vol. 85, no. 3, p. 325, 1988.

[13] R.E. Pandaleke, "Kajian Manfaat Tailing Untuk Bahan Bangunan Konstruksi”, Jurnal Tekno, vol. 7, no. 52, p. 75., 2010.

[14] R.E. Pandaleke, "Kajian Karakteristik Mortar Dengan Menggunakan Tailing dan Additive Sebagai Substitusi Parsial Semen", Jurnal Tekno Sipil, vol. 12, no. 60, p. 21, 2014.

[15] SNI 03-6825-2002, Metode Pengujian Kekuatan Tekan Mortar Semen Portland Untuk Pekerjaan Sipil, Jakarta: Badan Standar Nasional, 2002. 
This page is intentionally left blank 